\title{
Escaped farmed Atlantic salmon grow, migrate and disperse throughout the Arctic Ocean like wild salmon
}

\author{
Arne J. Jensen ${ }^{1, *}$, Sten Karlsson ${ }^{1}$, Peder Fiske ${ }^{1}$, Lars Petter Hansen ${ }^{2}$, Kjetil Hindar ${ }^{1}$, \\ Gunnel M. Østborg ${ }^{1}$
}

${ }^{1}$ Norwegian Institute for Nature Research, PO Box 5685 Sluppen, 7485 Trondheim, Norway
${ }^{2}$ Norwegian Institute for Nature Research, Gaustadalléen 21, 0349 Oslo, Norway

\begin{abstract}
This paper describes the first observations of escaped farmed Atlantic salmon Salmo salar in the Arctic Ocean. Among 138 individuals of Atlantic salmon captured at the west coast of the Spitsbergen Island at Svalbard in the period 2008-2010, 11 individuals (8\%) were classified as escaped farmed salmon based on genetic analysis and scale characters. The escaped individuals entered the ocean as a result of several different escape events. They had all escaped either at the smolt stage or early in the post-smolt stage, and had stayed one winter at sea. The growth of the escaped fish while at sea and their sizes were similar to those of wild fish captured at the same time in the same area. This suggests that farmed Atlantic salmon that have escaped early during the post-smolt period may grow, migrate, and disperse throughout the ocean like their wild counterparts, and survive to adulthood.
\end{abstract}

KEY WORDS: Salmo salar $\cdot$ Salmon farming $\cdot$ Svalbard $\cdot$ Genetic assignment $\cdot$ Distribution

\section{INTRODUCTION}

Farming of Atlantic salmon Salmo salar commenced in the early 1960s, and by 1982 the worldwide total annual production of farmed Atlantic salmon exceeded catches of wild Atlantic salmon (Mills 1989). Since then, the annual production of farmed salmon has increased to just over 1.6 million $t$ (in 2011), whereas annual catches of wild salmon have decreased to <2000 t (ICES 2012). Norway and Chile produce the majority of the farmed salmon, followed by the United Kingdom, Canada, and the Faroe Islands (ICES 2012). In general, pre-smolts are produced in fresh water in land-based hatcheries. At the smolt stage they are transferred to cages in the sea in coastal areas. Most escapes result from structural failures of equipment, with fewer caused by inadequate operational procedures or external factors (Jensen et al. 2010). Structural failures may arise

*Email: arne.jensen@nina.no from severe environmental forces caused by strong winds, waves and currents, which may occur in combination with component fatigue or human error in the way farm installations have been installed or operated (Jensen et al. 2010).

It is not known how many Atlantic salmon have escaped from farms in the North East Atlantic. The reported numbers of escapees from Norwegian salmon fish farms, however, varied between 111000 and 921000 in the period 2001-2010 (Fiskeridirektoratet 2012). Although this is a low proportion of the farmed salmon, it is large relative to the sizes of populations of wild salmon. In the same period the estimated number of salmon returning to the coast in the North East Atlantic varied between 1.6 and 2.7 million individuals (ICES 2012, their Tables 3.3.4.1 \& 3.3.4.2). Methods for identification of farm escapees from their scales and morphological characters have been developed (Lund \& Hansen 1991, Fiske et al. 2005), and

(C) The authors 2013. Open Access under Creative Commons by Attribution Licence. Use, distribution and reproduction are unrestricted. Authors and original publication must be credited. 
percentages of farm escapees observed in the catch samples taken in the Norwegian coastal bag net fisheries in the same period (2001-2010) was estimated to vary between 21 and $33 \%$ (ICES 2012). High proportions (up to $43 \%$ ) of escaped farmed salmon were observed in a fishery north of the Faroe Islands, which was closed in 1996 (Hansen et al. 1999). In Norwegian rivers farmed salmon are more abundant in autumn (i.e. during spawning) than during summer, usually with average proportions of 5-20\% and $1-5 \%$, respectively (Fiske et al. 2006), mainly because farmed salmon ascend fresh water to spawn later in the year than wild salmon (Eriksson \& Eriksson 1991, Gausen \& Moen 1991, Lund et al. 1991).

Recently, a set of genetic markers (single nucleotide polymorphisms, SNPs) has been developed to differentiate between Norwegian farmed and wild Atlantic salmon, regardless of their population of origin (Karlsson et al. 2011). This genetic tool will enable studies of the genetic introgression of escaped farmed salmon into populations of wild salmon, and it will also complement the use of analysis of scales to identify escaped farmed salmon. For example, if scale samples are missing or of poor quality (e.g. only replacement scales are available), or if farmed salmon originate from reproduction between escaped farmed salmon in the wild, scale analysis may fail. In addition, because scale analysis reveals the rearing environment, and not the genetic origin, scale analysis may not differentiate between farmed salmon escaping at the smolt stage and stocked salmon smolts. Thus, genetic analysis may be successful in identifying escaped farmed salmon or salmon of farmed origin.

The first reported observation of Atlantic salmon in the Arctic Ocean off Svalbard was made in 2002 (Berge et al. 2005). During the last $10 \mathrm{yr}$, a limited gill net fishery for Atlantic salmon has been developed on the west coast of Spitsbergen. In the present study, we analysed the occurrence of escaped farmed Atlantic salmon in catches from this fishery. During the autumn months of 2008 to 2010, scale samples or fish tissues of 138 Atlantic salmon were collected, and these individuals were classified as wild or farmed by image analyses of the scales as well as by genetic methods.

\section{MATERIALS AND METHODS}

\section{Study site}

The Arctic Ocean west of Svalbard is characterised by the warm West Spitsbergen Current, a branch of the Norwegian Atlantic Current. On reaching the latitude of West Spitsbergen, the temperature in the core of the Atlantic water off the shelf break ranges between 2.5 and $5^{\circ} \mathrm{C}$ and the salinity may typically be between 35.0 and 35.1 psu (Blindheim 2004). The warm waters of this current form the northernmost ice-free area in the Arctic. The strength of the West Spitsbergen Current is mainly driven by major wind systems and the densification of water masses by cooling at higher latitudes, and strong currents in this area are associated with high North Atlantic Oscillation (NAO) winter indexes (Blindheim 2004). These temperatures are around the lower preferred sea temperature of $\sim 4^{\circ} \mathrm{C}$ of Atlantic salmon suggested by Reddin (1985). In fresh water, juvenile Atlantic salmon survive in temperatures between 0 and $27.8^{\circ} \mathrm{C}$ (Elliott 1991), and optimum temperatures for growth are 16 to $20^{\circ} \mathrm{C}$ (Jonsson et al. 2001). Similar data are not available for the marine life of Atlantic salmon. Temperatures experienced at sea are, however, within a more narrow range. In the northeast Atlantic, most post-smolts were caught by floating trawls during summer at sea surface temperatures (SST) between 8 and $11^{\circ} \mathrm{C}$, and at salinities > 35 psu (Holm et al. 2003, 2004, Jensen et al. 2012). The upper preferred temperature at sea is suggested to be $\sim 12^{\circ} \mathrm{C}$ (Alm 1958).

During September and October 2008 to 2010, 138 individuals of Atlantic salmon (42, 41 and 55 in 2008, 2009 and 2010, respectively) were captured with gill nets in the Advent Fjord, close to the city of Longyearbyen on the west coast of Spitsbergen (78 $15^{\prime} \mathrm{N}$,

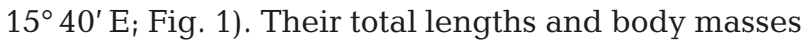
(round weight in 2009 and 2010, gutted weight in 2008) were determined, and a scale or tissue sample was retrieved from each individual.

\section{Age and growth analysis}

Age and growth data were obtained from image analysis of scales. Usually 4 to 6 scales collected from the standard area close to the lateral line between the dorsal fin and the adipose fin of each specimen were mounted on a cellulose acetate slide by pressing them with a roller. A microscope mounted digital camera (Nikon DS-Ri1) was used to record a highresolution (12.7 Mpx) image of one of the impressions. The Atlantic salmon were classified as being wild or farmed on the basis of growth patterns on their scales (Lund \& Hansen 1991, Fiske et al. 2005).

The Fulton's condition factor $(K)$ was estimated as $K=10^{5} \times W L^{-3}$, where $W$ is body mass in $g$ and $L$ is length in mm (Ricker 1975). 


\section{Genetic analysis}

Genomic DNA was obtained from 3 to 4 scales from each specimen, using the DNA extraction robot GeneMole ${ }^{\circledR}$, and following the MoleStrip ${ }^{\mathrm{TM}}$ DNA tissue protocol. All specimens were assayed for 99 nuclear SNPs. All PCR amplifications were carried out in 4 multiplexes, with 26, 26, 18, and 29 SNPs in each. Primer extension reactions followed recommendations from Sequenom (available at www. sequenom.com; accessed 15 Dec 2012). Fragment sizes were separated and identified using Sequenom MassARRAYTM analyzer (Autoflex mass spectrometer). The MassARRAYTM RT v3.4 software was used to perform the genotyping in real time depending on the presence or absence of a mass peak in expected mass range for each locus (Tang et al. 1999). Reliable genotypes were obtained from 76 of the SNPs, and the remaining SNPs either failed to amplify or produced unreliable genotype clusters. Of

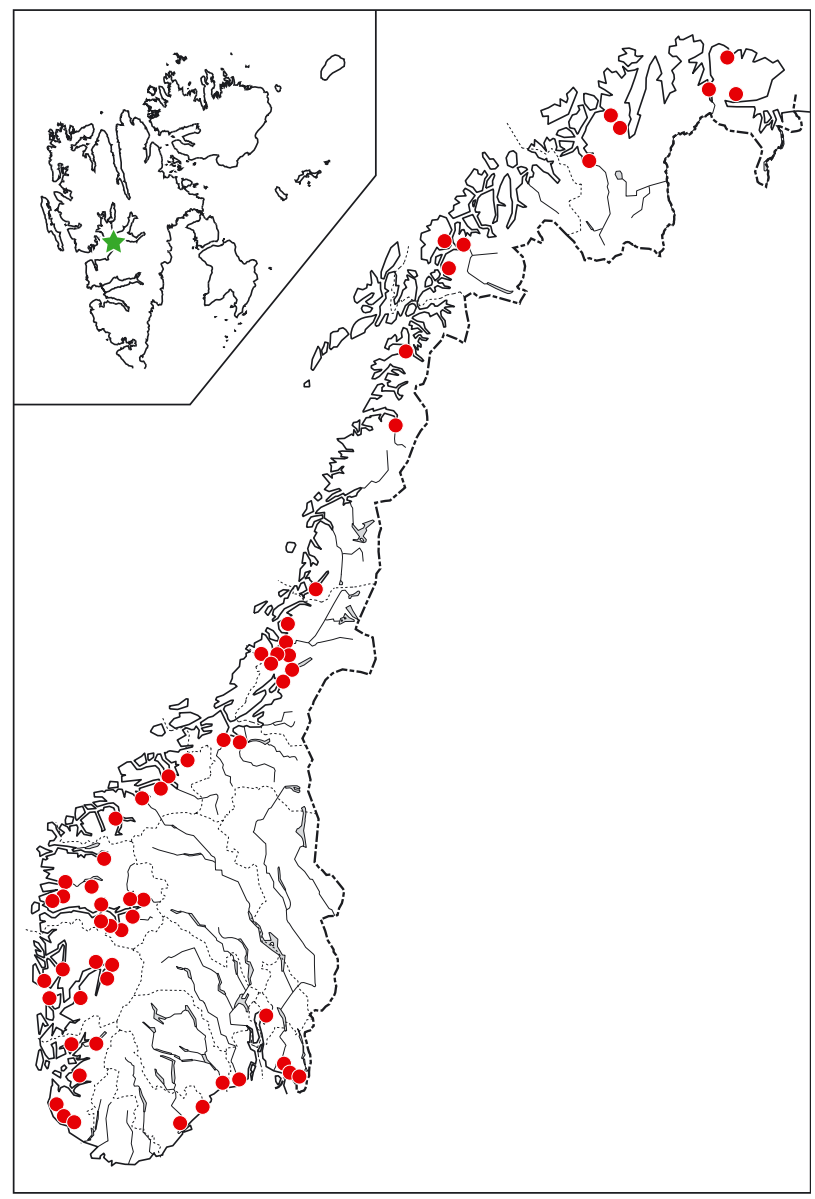

Fig. 1 Svalbard (upper left) and Norway. Location at Svalbard where Atlantic salmon were captured by gillnets $(\star)$, and 60 Norwegian Atlantic salmon populations included in the genetic baseline ( $\bullet$ ) the 76 SNPs, 59 were SNPs previously identified as being collectively diagnostic in differentiating between farmed and wild Atlantic salmon (Karlsson et al. 2011), whereas 17 SNPs represent a random set of putatively neutral SNPs. Because not all the top 60 diagnostic SNPs listed by Karlsson et al. (2011) could successfully be assayed for the MassARRAY, additional SNPs were selected from the extended list of 200 diagnostic SNPs (Karlsson et al. 2011). Specifically, 43 of the 59 diagnostic SNPs were included from the list of 60 SNPs, and the additional 16 were included from the list of 200 SNPs with the greatest potential to collectively differentiate between farmed and wild Atlantic salmon (Karlsson et al. (2011).

Among the fish caught in the waters off Svalbard, farmed salmon were identified using the multi-locus genotype data for the above-mentioned 59 SNPs. Genetic data for the same SNPs in 12 strains of farmed salmon (Karlsson et al. 2011) were used as a reference for farmed salmon. We applied 3 analytic approaches to identify escaped farmed salmon.

The first approach to identify escaped farmed salmon involved assigning individuals to either of 2 assumed populations $(k=2)$ using STRUCTURE (Pritchard et al. 2000), with separate runs for each of the 12 reference populations of farmed salmon. We applied 10000 repetitions as burn-in, and 10000 repetitions after burn-in, and no a priori information about the origins of the individuals. The individuals with the lowest probability $(\mathrm{p}<0.5)$ of belonging to wild populations were assumed to be of farmed origin. STRUCTURE assigns individuals based on their multi-locus genotype to populations while minimising linkage disequilibrium and maximising conformance to Hardy-Weinberg equilibrium (Pritchard et al. 2000). Because there may be large genetic differences between the different farmed strains (Karlsson et al. 2011), a farmed salmon may show a genetic signature more similar to the wild populations if compared to a farmed strain from which it does not originate, while showing a genetic signature similar to the farmed strain from which it does originate. Hence, highest estimate for belonging to a farmed strain among the 12 farmed strains tested is likely the most reliable estimate for identifying a farmed fish. At the same time a fish of true wild origin is expected to assign poorly to all of the farmed strains (Karlsson et al. 2011).

The second approach involved individual genetic assignment (GeneClass2, Piry et al. 2004) of Atlantic salmon caught off Svalbard to either 60 wild salmon populations or 12 farmed strains using the direct assignment option and the Bayesian method (Ran- 
nala \& Mountain 1997). This approach finds the most likely population (from a set of reference populations) from which the multi-locus genotype of an individual may originate (Cornuet et al. 1999).

The third approach involved exclusion of individuals suspected as being of farmed origin using individual genetic assignment with probability computation (Paetkau et al. 2004), with only the 12 farmed salmon strains as reference populations. Individuals for which the probability of having been farmed was $\leq 0.01$ were ruled out from being of farmed origin.

\section{RESULTS}

Among the 138 Atlantic salmon collected at Svalbard, scales could be analysed from 131 individuals, whereas 137 individuals were analysed genetically. Analyses of the scales characterised 9 fish as being of farmed background, and 119 as wild. The origin of 3 individuals could not be determined with reasonable certainty. Of the 9 individuals classified as farmed fish, 8 had escaped as smolts or early in the postsmolt period, at times when their total lengths were back-calculated to have been between 161 and $282 \mathrm{~mm}$. The time of escape of the last individual could not be determined because of the poor quality of the scales collected.

Of the 137 individuals of Atlantic salmon assayed for genetic variation at 76 SNP loci, 9 had a scoring rate $<80 \%$ (i.e. amplification failed in $>16$ of the assays) and these individuals were excluded from further analyses. Individual discrimination to either of the 2 assumed types of populations (12 farmed strains or the samples from Svalbard), using STRUC-

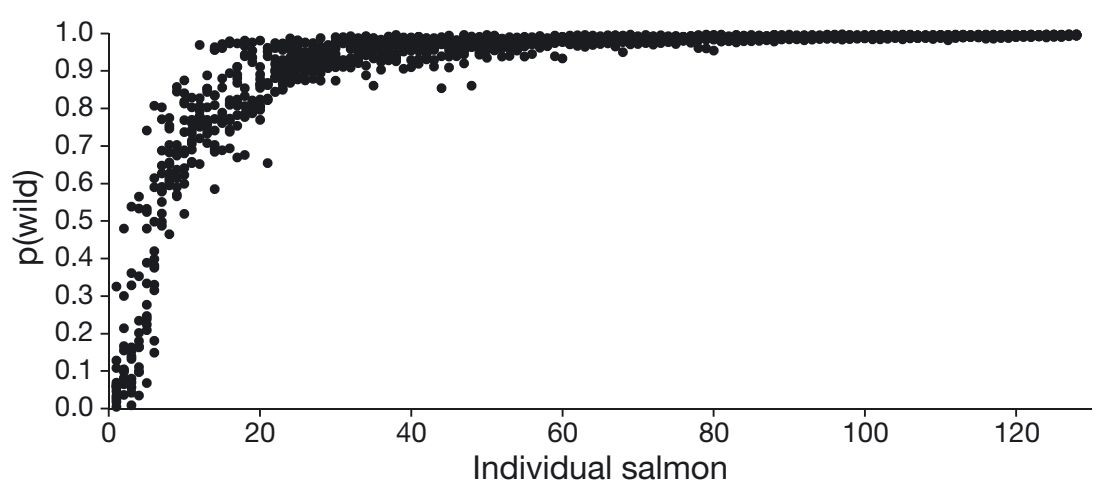

Fig. 2. Salmo salar. Probability of being of wild origin for each of 128 individuals of Atlantic salmon captured off Svalbard. Each individual has 12 different estimates (data points in a vertical line for each individual salmon) from pairwise comparisons with each of the 12 farmed strains
TURE, indicated that 9 fish had a probability of $<0.5$ of being of wild origin (Fig. 2). From scale analysis, 6 of these individuals were characterized as having farmed background, 1 as wild, 1 uncertain, and 1 could not be analysed. The 1 fish characterised as wild from scale analysis had a probability from genetic analysis of being a wild fish of 0.487 (Sval_09_35), and might be a hybrid between farmed and wild salmon. The 2 remaining individuals, which could not be classified from their scales, had very low probabilities of being wild (Sval_10_51: $\mathrm{p}=0.036$ and Sval_10_54: $p=0.068)$; these were therefore classified as escaped farmed salmon. All individuals for which the probability of being wild was $>0.8$ were classified as wild on the basis of scale analysis ( $\mathrm{n}=$ 106), except for 7 individuals whose scales were lacking or were of too poor quality to be analysed. Among 13 individuals with probabilities between 0.5 and 0.8 of being of wild origin, 11 were classified as wild, whereas the remaining 2 were classified as farmed on the basis of scale analysis. One of them (Sval_ 09_24) had a probability of being wild close to 0.5 $(\mathrm{p}=0.519)$. The second one (Sval_10_36) had a probability of being wild of 0.787 , which is high relative to the majority of the fish classified as farmed salmon, but low relative to fish classified as wild. These 2 individuals are therefore more likely to be escaped farmed salmon than stocked salmon. One individual, which had been excluded from further genetic analysis (Sval_09_23), was characterised as a farmed salmon on the basis of analysis of its scales.

Following direct assignment of individual specimens, 2 individuals (Sval_09_08 and Sval_09_39) were assigned to 1 of 12 farmed strains, both of them among the 9 fish which had a probability $<0.5$ of being of wild origin using STRUCTURE.

Genetic assignment was used to estimate the probability that any single individual belonged to each one of the 12 farmed strains selected for in the analysis. The analysis showed that for 119 of the 128 individuals analysed, the average probability of belonging to these 12 strains was no higher than 0.01 , by which value we ruled out farm origin. In agreement with STRUCTURE, 8 of the remaining 9 individuals had a probability of $<0.5$ of being of wild origin, whereas for the remaining 1 (Sval_10_47), a probability of $\mathrm{p}=$ 0.877 was estimated from STRUCTURE (available at www.int-res.com/articles/ suppl/q003p223_supp.pdf). 


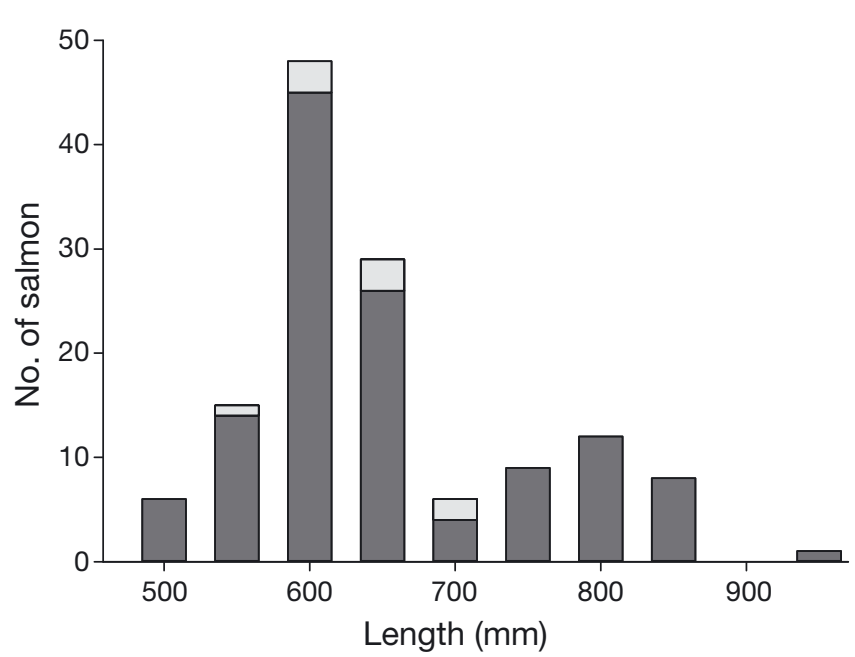

Fig. 3. Salmo salar. Length distribution of wild (dark grey) and escaped farmed (light grey) Atlantic salmon captured off Svalbard in the period 2008-2010

In general, the results from the genetic analyses using STRUCTURE and the visual analyses of the scales are in good agreement (see Table S1 in the supplement), which means that the fish classified as farmed or stocked as wild from scale analysis are commercial escaped farmed salmon, as revealed by the genetic analysis. In conclusion, 11 (8\%) of the 138 individuals of Atlantic salmon from Svalbard were classified as escaped farmed salmon.

Lengths and weights of the 11 individuals classified as escaped farmed salmon were 560 to $700 \mathrm{~mm}$ (Fig. 3) and 2.1 to $4.1 \mathrm{~kg}$, respectively. Of these fish, 1 was caught during 2008, 5 in 2009 and 5 in 2010. Each of the 6 individuals for which sea age could be determined had spent 1 winter at sea. For the remaining 5 individuals sea age could not be determined from scale analyses. Nonetheless, analysis of the lengths and weights of these individuals indicated that they were likely of the same sea age. Assessment of maturity of 8 of the 11 individuals at the time of capture indicated that all of them were immature.

Among the wild Atlantic salmon analysed, lengths, weights and sea ages varied between 505 and $925 \mathrm{~mm}$, 1.2 to $8.7 \mathrm{~kg}$, and 1 to 2 winters, respectively. The length distribution was bimodal (Fig. 3): $70 \%$ had stayed 1 winter at sea, and $30 \%$ had stayed 2 winters at sea. The mean $( \pm \mathrm{SE})$ condition factor $(K)$ for individuals with data on round weight was $1.17 \pm 0.17$ and $1.15 \pm 0.15$ for farmed and wild salmon, respectively, which was not significantly different (ANOVA $F_{1,88}=$ $0.164, p=687$ ). The length distribution of farmed Atlantic salmon was similar to that of wild Atlantic salmon that were 1 sea winter old (Fig. 3).

\section{DISCUSSION}

This is the first report of observations of escaped farmed Atlantic salmon in the Arctic Ocean. From 138 individuals captured at the west coast of Svalbard, 11 (8\%) were classified as escaped farmed fish. They were captured in 3 different years (2008 to 2010) and had escaped at the smolt stage or soon after being transferred to sea cages from fresh water. Hence, they represent Atlantic salmon from several different escape events.

Farmed Atlantic salmon were identified genetically by comparing the multi-locus genotype with the genetic composition of 12 different strains of farmed salmon. These strains represent the major farmed salmon strains used in Norway (Aqua Gen, Salmo Breed, Marine Harvest). All individuals characterised as farmed from their scales had escaped at the smolt stage or shortly thereafter, and hence may have originated either from the fish farming industry or from stocking of hatchery-reared smolts with parents of wild origin to strengthen the local salmon population. However, no major discrepancies were found between the results of the genetic analysis and the scales analysis, which means that the fish characterised as farmed salmon originated from the fish farming industry and not from stocking of hatchery reared smolts. No fish combined the characteristic of wild from scale analysis and farmed from genetic analysis, indicating that none of the fishes were of naturally reproduced farmed origin (spawning between pure farmed fish in the wild). Intermediate probabilities of being farmed and wild salmon were shown by 13 individuals: 2 of these were classified as farmed from scale analysis, and the remaining may represent hybrids between wild and farmed salmon or rare wild genotypes. The genetic analysis implemented in STRUCTURE gave the most reliable estimates of farmed and wild origin, and has an advantage in that the estimated probabilities of belonging to the populations can be translated to proportions of membership of the genome belonging to the populations (admixture). The analytical approaches implemented in GeneClass gave a weaker signal of farmed origin. In particular, only 2 individuals were assigned to a farmed strain using the direct assignment option. The option of estimating the probability of belonging to reference populations (in GeneClass) was to a larger extent in agreement with the results obtained by STRUCTURE and the scale analysis. This is because most wild salmon were excluded as being of farmed origin while most farmed salmon could not 
be excluded. Collectively all 3 analytical approaches proved useful for identification of farmed salmon.

All farmed Atlantic salmon had spent 1 winter at sea, and hence had escaped during 2007 to 2009. They were captured in September and early October $\sim 900 \mathrm{~km}$ away from the nearest river in which Atlantic salmon spawn, and the same distance away from the nearest fish farm. Still, if they had been sexually mature, some of the fish captured in September could have been able to migrate to fresh water to spawn during the same autumn. However, it is likely that all of them were immature, and hence would spend at least 1 more year at sea before spawning.

All farmed fish in this study escaped as smolts or early in the post-smolt period, and no individuals had escaped at later marine stages. According to official statistics (Fiskeridirektoratet 2012), 59\% of reported escapees from Norwegian fish farms during 2007 to 2009 had a body mass of $>1 \mathrm{~kg}$ at the time of their escape, whereas the escaped farmed salmon in the present study had escaped at a body length $<282 \mathrm{~mm}$ $(<250 \mathrm{~g})$. Experiments with the release of individually tagged sea ranched Atlantic salmon at different life stages and at different times of the year have demonstrated that individuals that escape during spring and summer have a higher survival rate than individuals that escape at other times of the year (Hansen \& Jonsson 1991). Atlantic salmon that escape during spring and summer also tend to return to the area from which they were released, whereas adult-escapee salmon tend to disperse more widely (Hansen \& Jonsson 1991, Hansen 2006, Skilbrei 2010a,b).

Escaped farmed salmon are found alongside wild salmon in Norwegian coastal areas and rivers (Gausen \& Moen 1991, Lund \& Hansen 1991). Hansen \& Jacobsen (2003) demonstrated that farmed escaped Atlantic salmon use the same feeding areas north of the Faroe Island as wild populations. Our study shows that common feeding grounds also exist off Svalbard, suggesting that farmed escaped salmon use the same feeding areas as wild salmon, and hence compete for the same resources at sea. Because of weaker homing instinct of escaped farmed salmon (Hansen \& Jonsson 1991, Hansen 2006, Skilbrei 2010a,b), we hypothesise that escaped farmed salmon may colonise new rivers more rapidly than wild salmon as climate change makes new habitats available to salmon.

Acknowledgements. This study was financed by the Norwegian Directorate for Nature Management and the Norwegian Institute for Nature Research (NINA), which is greatly acknowledged. We also wish to thank the Governor of Svalbard and local fishermen, especially F. Jakobsen, for help with collecting Atlantic salmon scale samples.

\section{LITERATURE CITED}

Alm G (1958) Seasonal fluctuations in the catches of salmon in the Baltic. ICES J Mar Sci 23:399-433

$>$ Berge J, Johnsen G, Nilsen F, Gulliksen B, Slagstad D (2005) Ocean temperature oscillations enable reappearance of blue mussels Mytilus edulis in Svalbard after a 1000 year absence. Mar Ecol Prog Ser 303:167-175

Blindheim J (2004) Oceanography and climate. In: Skjoldal HR (ed) The Norwegian sea ecosystem. Tapir Academic Press, Trondheim, p 65-96

> Cornuet JM, Piry S, Luicart G, Estoup A, Solignac M (1999) New methods employing multilocus genotypes to select or exclude populations as origins of individuals. Genetics 153:1989-2000

Elliott JM (1991) Tolerance and resistance to thermal stress in juvenile Atlantic salmon, Salmo salar. Freshw Biol 25: 61-70

Eriksson T, Eriksson LO (1991) Spawning migratory behaviour of coastal-released Baltic salmon (Salmo salar). Effects on straying frequency and time of river ascent. Aquaculture 98:79-87

Fiske P, Lund RA, Hansen LP (2005) Identifying fish farm escapees. In: Cadrin SX, Friedland KD, Waldman JR (eds) Stock identification methods: applications in fishery science. Elsevier Academic Press, Amsterdam, p 659-680

Fiske P, Lund R, Hansen LP (2006) Relationships between the frequency of farmed Atlantic salmon, Salmo salar L., in wild salmon populations and fish farming activity in Norway, 1989-2004. ICES J Mar Sci 63:1182-1189

Fiskeridirektoratet (2012) Rapporterte rømminger til Fiskeridirektoratet, available at www.fiskeridir.no/akvakultur/ roemming/rapporterte-roemminger-til-fiskeridirektoratet (accessed 19 Dec 2012)

Causen D, Moen V (1991) Large-scale escapes of farmed Atlantic salmon (Salmo salar) into Norwegian rivers threaten natural populations. Can J Fish Aquat Sci 48: 426-428

> Hansen LP (2006) Migration and survival of farmed Atlantic salmon (Salmo salar L.) released from two Norwegian fish farms. ICES J Mar Sci 63:1211-1217

> Hansen LP, Jacobsen JA (2003) Origin and migration of wild and escaped farmed Atlantic salmon, Salmo salar L., in oceanic areas north of the Faroe Islands. ICES J Mar Sci 60:110-119

- Hansen LP, Jonsson B (1991) The effect of timing of Atlantic salmon smolt and post-smolt release on the distribution of adult return. Aquaculture 98:61-67

Hansen LP, Jacobsen JA, Lund RA (1999) The incidence of escaped farmed Atlantic salmon, Salmo salar L., in the Faroese fishery and estimates of catches of wild salmon. ICES J Mar Sci 56:200-206

Holm M, Holst JC, Hansen LP, Jacobsen JA, O'Maoiléidigh N, Moore A (2003) Migration and distribution of Atlantic salmon post-smolts in the North Sea and North East Atlantic. In: Mills D (ed) Salmon at the edge. Blackwell Science, Oxford, p 7-23

Holm M, Hansen LP, Holst JC, Jacobsen JA (2004) Atlantic Salmon, Salmo salar L. In: Skjoldal HR (ed) The Norwegian sea ecosystem. Tapir Academic Press, Trondheim, p 266-306

ICES (2012) Report of the Working Group on North Atlantic Salmon (WGNAS). ICES WGNAS CM 2012/ACOM 9:320 Jensen $\varnothing$, Dempster T, Thorstad EB, Uglem I, Fredheim A (2010) Escapes of fishes from Norwegian sea-cage aqua- 
culture: causes, consequences and prevention. Aquacult Environ Interact 1:71-83

Jensen AJ, O'Maoiléidigh N, Thomas K, Einarsson SM, Haugland M (2012) Smolt age and fine-scale marine growth of Atlantic salmon post-smolts in the Northeast Atlantic. ICES J Mar Sci 69:1668-1677

Jonsson B, Forseth T, Jensen AJ, Næsje TF (2001) Thermal performance of juvenile Atlantic salmon, Salmo salar L. Funct Ecol 15:701-711

Karlsson S, Moen T, Lien S, Hindar K (2011) Generic genetic differences between farmed and wild Atlantic salmon identified from a 7K SNP-chip. Mol Ecol Resour 11 (Suppl 1):247-253

Lund RA, Hansen LP (1991) Identification of wild and reared Atlantic salmon, Salmo salar L., using scale characters. Aquacult Fish Manag 22:499-508

Lund RA, Økland F, Hansen LP (1991) Farmed Atlantic salmon (Salmo salar) in fisheries and rivers in Norway. Aquaculture 98:143-150

Mills D (1989) Ecology and management of Atlantic salmon. Chapman \& Hall, London

Paetkau D, Slade R, Burden M, Estoup A (2004) Genetic assignment methods for the direct, real-time estimation of migration rate: a simulation-based exploration of accuracy and power. Mol Ecol 13:55-65

Editorial responsibility: Tim Dempster, Trondheim, Norway
Piry S, Alapetite A, Cornuet JM, Paetkau D, Baudouin L, Estoup A (2004) GeneClass2: a software for genetic assignment and first-generation migrant detection. J Hered 95:536-539

Pritchard JK, Stephens M, Donnely P (2000) Inference of population structure using multilocus genotype data. Genetics 155:945-959

Rannala B, Mountain JL (1997) Detecting immigration by using multilocus genotypes. Proc Natl Acad Sci USA 94: 9197-9201

Reddin DG (1985) Atlantic salmon (Salmo salar) on and east of the Grand Bank. J Northwest Atl Fish Sci 6:157-164

Ricker WE (1975) Computations and interpretation of biological statistics of fish populations. Bull Fish Res Board Can 191

Skilbrei OT (2010a) Adult recaptures of farmed Atlantic salmon post-smolts allowed to escape during summer. Aquacult Environ Interact 1:147-153

Skilbrei OT (2010b) Reduced migratory performance of farmed Atlantic salmon post-smolts from a simulated escape during autumn. Aquacult Environ Interact 1: $117-125$

Tang K, Fu DJ, Julien D, Braun A, Cantor CR, Kösner H (1999) Chip-based genotyping by mass spectrometry. Proc Natl Acad Sci USA 96:10016-10020

Submitted: January 4, 2013; Accepted: March 20, 2013

Proofs received from author(s): April 19, 2013 